\title{
A Spatial Difference-in-Differences Approach to Evaluate the Efficiency of Urban Green Innovation under the Pilot Policy of Combining Technology and Finance
}

\author{
Xuefang Zhang, Wei Dai* \\ School of Economics and Management, Hubei Polytechnic University, Huangshi, Hubei, China \\ *Corresponding Author.
}

\begin{abstract}
With the "Pilot Policy of Combining Technology and Finance" implemented in 2011 and 2016 as a quasi-natural experiment, taking the panel data of a total of 285 cities in China in 2003-2018 as an example, the spatial difference-in-differences models are used to evaluate the impact of pilot policy of combining technology and finance on urban green innovation efficiency. The study found that technology and finance pilot policies obviously increase the regional green innovation level. At the same time, local governments play an important role in regional green innovation practice activities, involving both positive and negative roles. The research herein provides quantitative support for evaluating the effects of technology and finance pilot policies, and provides a reference for the further innovation and promotion of the technology and finance pilot policies.
\end{abstract}

Keywords:technology finance, green innovation, spatial difference-in-differences, policy evaluation

\section{Introduction}

Technology is the primary productive force. Technological innovation facilitates the formation of endogenous growth momentum in the economy, avoids periodic fluctuations caused by the law of diminishing marginal returns of production factors, thus allowing sustainable growth of the economy. As the lubricant of modern economic development, finance is an important part of the innovation-driven development model. In recent years, a series of innovation policies issued by the government, the continuous increase of R\&D investment by enterprises, and the continuous emergence of technology-based start-up companies all indicate that innovation is more and more universally recognized by the entire society, which is a necessary path for China to move from a stage of high-speed growth to a stage of high-quality development. Zhang (2018)[1]pointed out that regional differences in the development level of science and technology financial ecosystem lead to different development speed of innovation activities in various regions. This also shows that the pilot policy of combining technology and finance indeed stimulate the innovation and development activities of different regions to some extent. After more than 30 years of rapid economic growth in China, traditional industries and old economic development models have reached the ceiling of industry growth. Before the establishment of a new mode of economic growth, the reality of slowing economic growth and gradual shortage of resources has become the new normality on the road of current domestic economic growth. In view of this, since the 18th National Congress of the Communist Party of China, the "Strategy of Vigorously Promoting Green and Low-Carbon Circular Development and Innovation-Driven Development"has been proposed. The national "Thirteenth Five-Year" plan puts forward new socialist economic development concepts of "innovation, coordination, green, openness, and sharing". The plan clearly combines green and innovation for the first time. Urban green economy and innovation economy present a trend of mutual promotion and mutual integration under the new normality of our economic development. Green innovation has become a new goal, new feature, and new model to address the plight of slowdown in our urban economic growth. In this context, has the government's technology and finance pilot policy promoted the development of urban green and innovative economy? If so, what mechanisms and channels are used to influence urban green innovation activities? Is the impact significant? Judging from the existing research, there is no direct and complete answer and these questions are the main aspects that we attempt to study.

ISSN: 0010-8189

(C) CONVERTER 2021

www.converter-magazine.info 


\section{Data and Model Design}

\subsection{Variable definition}

\subsubsection{Explained variables}

Based on the research results of predecessors and scholars, we adopt undesired output-based SBM model of Tone (2004) [2] to measure the green innovation efficiency level of each city. Drawing on relevant research of Wang et al. (2020) [3],we selects the number of employees in scientific research and technical services, geological surveys, water conservancy environment and public facilities management as environmental science and technology labor input $(L t)$; government science and technology expenditures are used as science and technology capital investment $(K t)$, while electricity consumption throughout the year is used as energy input $(N)$. The expected output variables are measured by the regional gross product (economic output, $Y e$ ), the number of patent applications granted in each city (innovative output, $Y t$ ), and the decontamination rate of domestic waste (green output, $Y g$ ); the undesired output is mainly measured by three indicators of industrial wastewater (waste) discharge in each city, industrial sulfur dioxide $\left(\mathrm{SO}_{2}\right)$ discharge, and industrial smoke (dust) discharge.

\subsubsection{Main explanatory variables}

On October 20, 2011, document (Guokefacai [2011] No.539) released by the Ministry of Science and Technology of China identified the first batch of pilot areas for the combination of technology and finance, including 16 regions: Zhongguancun National Independent Innovation Demonstration Zone, Tianjin City, Shanghai City, Jiangsu Province, "Hangzhou, Wenzhou, Huzhou, Ningbo" in Zhejiang Province, Hefei-Wuhu-Bengbu independent innovation comprehensive experimental zone in Anhui Province, Wuhan City, Changsha High-tech Zone, "Guangzhou, Foshan, Dongguan" in Guangdong Province, Chongqing City, Chengdu High-tech Zone, Mianyang City, Guanzhong -Tianshui Economic Zone (Shaanxi), Dalian City, Qingdao City, Shenzhen City, etc.we selects 40 cities therefrom as pilot cities. On June 14, 2016, document Guokefazi [2016] No.183 selected 9 cities across the country as the second batch of pilot cities. In the studies of Ma and Li (2019)[4], Zheng et al. (2020)[5], samples from 2016 were selected, while the second batch of pilot cities were treated as non-pilot cities. Since the sample period of this paper is extended to 2018, if the second batch of pilot cities is treated artificially as non-pilot cities, it is impossible to conclude convincing results. Therefore, we consider incorporating the first batch and the second batch of pilot cities into the econometric analysis at the same time.

When evaluating the effect of the pilot policy of combining technology and finance, 49 cities from the first and the second batch of pilot areas were considered as the treatment group, and the remaining 236 cities without the pilot program accordingly became the control group. Each pilot city had prepared well before the release of the policy document. Therefore, we set the effective time of the treatment group as the release time of the first and second batch pilot policies, namely 2011 and 2016. The policy dummy variable $D_{i t}$ is generated. When $D_{i t}=1$, it indicates that city $i$ has obtained the pilot qualification and is in the pilot period; when $D_{i t}=0$, it indicates that city $i$ has not obtained the pilot qualification or is in the non-pilot period.

\subsubsection{Control variables}

Drawing upon related studies of Ma and Li (2019) [4], Zheng et al. (2020) [5],we consider adding the following control variables to the model: (1) Innovation results (Ininno), which is calculated by totaling the number of granted patents and granted utility model patents and taking a logarithmic value. The most direct contribution to the innovation efficiency of a region is the innovation results created in that region. The more innovation results, the higher the innovation efficiency. (2) Government expenditure ( $g o v)$, which is indicated by the proportion of local government budget expenditure in GDP. The green development of a region is inseparable from the local government's multi-faceted investment, and government expenditure is not only reflected in the direct effect of science and technology expenditure on green development. At the same time, the development of urban education level, the improvement of public infrastructure, the increase of government public service level and work efficiency can also create a positive indirect effect on the green innovation efficiency of a city. (3) Environmental pollution $\left(\operatorname{lns}_{2}\right)$, which uses the logarithmic value of industrial sulfur dioxide emissions as a proxy variable. The 
motivation for companies to implement green innovation depends on the government's control over environmental protection. Appropriate and strict environmental protection policies can help stimulate companies to implement green innovation. (4) Industrial structure (instru), which is indicated by the proportion of tertiary industry output value in GDP. Upgrading of industrial structure further promotes the increase in efficiency of enterprise technological innovation. (5) Urban development level (lnpgdp), which is measured by the logarithmic value of urban per capita GDP. A city with higher economic level has more funds for technological upgrades, and residents will have higher requirements for products and the environment, which will promote the improvement of green innovation level in the region. (6) Traditional finance (finance), which is indicated as the proportion of deposits and loans of various regions in GDP. The reason why the government proposes a pilot policy of combining technology and finance is that traditional finance can no longer meet the rapidly growing financial needs of society, and social and economic development requires further innovation of the financial system.

\subsection{Data sources}

Considering completeness and availability of data, we select 4560 observations from 285 cities across the country in 2003-2018. All the indicators selected for explained variables and control variables come from "China Urban Statistical Yearbook (2004-2019)", and the number of granted patent applications derives from China Research Data Service Platform (CNRDS). Linear interpolation is used to fill in the omitted values. At the same time, the GDP deflator of each province in 2000 is used to deflate the GDP of each province. The descriptive statistics of related variables are shown in Table 1.

Table 1 Descriptive statistics

\begin{tabular}{cccccc}
\hline Variables & Observations & Mean & S.D. & Min & Max \\
\hline$L t$ & 4560 & 18309 & 44175 & 200 & 839572 \\
$K t$ & 4560 & 6.487 & 24.9682 & 0 & 550 \\
$N$ & 4560 & 90.151 & 150 & 0 & 1.571 \\
$Y e$ & 4560 & 1.140 & 1.740 & 26.836 & 2.3101 \\
$Y t$ & 4560 & 2922 & 8544 & 1 & 139739 \\
$Y g$ & 4560 & 79.62 & 29.04 & 0 & 100 \\
waste & 4560 & 6631 & 9152 & 6.950 & 93814 \\
so 2 & 4560 & 49969 & 56860 & 2 & 683162 \\
dust & 4560 & 30983 & 114000 & 34 & 5200100 \\
Gino & 4560 & 0.459 & 0.296 & 0.001 & 1 \\
$D$ & 4560 & 0.076 & 0.265 & 0 & 1 \\
Ininno & 4560 & 5.822 & 1.904 & 0 & 11.570 \\
gov & 4560 & 0.191 & 0.219 & 0.015 & 6.041 \\
Inso ${ }_{2}$ & 4560 & 10.010 & 1.825 & 0 & 13.430 \\
instru & 4560 & 0.379 & 0.618 & 0.007 & 41.390 \\
Inpgdp & 4560 & 9.874 & 0.784 & 4.356 & 15.280 \\
finance & 4560 & 2.360 & 1.973 & 0.015 & 50.430 \\
\hline
\end{tabular}

2.3 Spatial difference-in-differences (SDID) model specifications

In recent years, foreign countries have widely used spatial difference-in-differences (SDID) models in empirical analysis such as regional policy evaluation and causal inference, while domestic research on the application of 
spatial difference-in-differences models is still in its infancy. By referring to and studying previous researches, this study further explores the impact of the pilot policy of combining technology and finance on green innovation efficiency in China based on the SDID model. Referring to Sunak and Madlener (2016) [6], we cite the spatial autocorrelation model (SAC/SARAR) and the spatial Dubin error model (SDEM) to control the spatial correlation and the spatial clustering effect of unobserved variables, respectively. At the same time, to compare with the traditional DID model, we also added the ordinary spatial fixed effects model (SFM). As shown in equation (1), most of the existing research literature uses SFM as the standard estimation method of DID, for instance, by adding regional dummy variables to the model to indicate the influence of those unobserved variables and prevent biased estimate caused by omitted variables.

$$
\text { Gino }_{i t}=\alpha_{0}+\theta D_{i t}+\sum \beta_{k} z_{k}+u_{i}+\gamma_{t}+\varepsilon_{i t}
$$

Where, Gino is the green innovation efficiency index of the explained variable, $D_{i t}$ indicates whether the "treated"dummy variable is also the main explanatory variable of this paper, $Z=\left\{z_{1}, z_{2}, \ldots, z_{k}\right\}^{\mathrm{T}}$ represents a series of control variables, $u_{i}$ and $\gamma_{t}$ represent space and time fixed effects, respectively. The subscripts $i$ and $t$ denote the $i$-th city and the $t$-th year, respectively.

Although the introduction of spatial fixed effects in the model can reduce the estimation bias caused by potential omitted variables (unobserved variables) to a certain extent, it still cannot effectively explain the effect of spatial correlation (Anselin and Arribas-Bel, 2013) [7]. If the spatial correlation of observations cannot be effectively controlled, it may lead to biased or invalid estimates (Griffith and Anselin, 1989)[8]. Regarding the impact of spatial correlation, literature studies have shown that different models can control the spatial characteristics of unobserved values by adding spatial lag terms to the explained variables, explanatory variables, and error terms (Lesage and Pace, 2009) [9]. From an empirical point of view, due to the spatial correlation and omitted spatial clustering variables in the model, most researchers prefer spatial econometrics (Lerbs and Oberst, 2014) [10]. Therefore, we will consider the spatial correlation of the explained variables, explanatory variables and error terms in the model construction.

First, considering the potential spatial correlation between the dependent variable and the error term, establishing a spatial autoregressive model (SAC/SARAR) with a spatial autoregressive error term. The model form is shown in equation (2):

$$
\text { Gino }_{i t}=\alpha_{0}+\theta D_{i t}+\sum \beta_{k} z_{k}+\rho \sum w_{i j} \text { inoo }_{i t}+u_{i}+\gamma_{t}+\mu_{i t}
$$

Where, $u_{i t}=\lambda W u_{i t}+\varepsilon_{i t}$. The difference from equation (1) is that equation (2) introduces a spatial autoregressive process determined by $W$ in the dependent variable and error term. We use the most commonly used rear neighbor matrix (W01) and distance attenuation matrix (WD2) as a weight matrix that characterizes the neighboring relationship between regions. The former is generated depending on the adjacency of the geographical boundaries between cities, and the latter is obtained by calculating the reciprocal of the square of the distance between the centers of the two cities. The coefficients $\rho$ and $\lambda$ in equation (2) represent the spatial correlation between the dependent variable and the error term respectively. When $\rho=0$, equation (2) becomes the spatial error model (SEM). When $\lambda=0$, equation (2) is simplified to a spatial autoregressive model (SAR/SLM). Therefore, the SAC/SARAR model includes both SLM/SAR and SEM models.

In addition to the spatial autocorrelation that may exist in the dependent variable itself and the unobserved variable, the spatial correlation in the explanatory variable should also be considered. For example, certain characteristics of neighboring cities that affect the efficiency of green innovation may create local spillover effects on the level of green innovation in a given city. By adding the spatial lag term of explanatory variables to the model, it is possible

ISSN: 0010-8189

(C) CONVERTER 2021

www.converter-magazine.info 
to control these local effects. Since SAC/SARAR model does not include the spatial lag term of explanatory variables, most literature will choose spatial Dubin model (SDM) instead. The SDM model consists of the spatial lag term in the explanatory variable and the spatial autoregressive term of the dependent variable or the spatial autoregressive term of the error term. In this paper, the SDM model containing the spatial error autoregressive term is selected to form the spatial Dubin error model (SDEM). The model form is shown in equation (3):

$$
\text { Gino }_{i t}=\alpha_{0}+\theta D_{i t}+\sum \beta_{k} z_{k}+\sum \sum w_{i j}\left(D_{i j}+z_{i j}^{k}\right) \gamma+u_{i}+\gamma_{t}+\mu_{i t}(3)
$$

Where, $u_{i t}=\lambda W u_{i t}+\varepsilon_{i t}$, all other variables are the same as in equations (2) and (1). The spatial correlation of all explanatory variables is indicated by $\gamma$.

\section{Empirical Results}

\subsection{Spatial Difference-in-differences estimation}

This study concludes empirical estimation results based on three models. The AIC criterion, the log-likelihood estimate and the log-likelihood ratio test (LR-test) shown in Table 2 indicate the overall fit of the model and the significance of the spatial correlation coefficient. According to the estimated values of AIC and log-likelihood, the three models have quite close overall fit. Where, the SAC/SARAR model has the best explanatory power, and the SFM model has a slightly weaker explanatory power. In addition, the LR test also shows that the spatial measurement model is more suitable for the study of this paper than the spatial fixed effects model (SFM). Moran's $I$ test and LM test show that although urban fixed effects are added to the SFM model, there is still a spatial correlation. Both two test results are significant at the $1 \%$ level, indicating that the dependent variables and error terms of the model have a strong spatial dependence. Therefore, SFM model cannot effectively control the effect of spatial correlation.

Table 2 Results of spatial diff-in-diff models

\begin{tabular}{|c|c|c|c|}
\hline & SFM & SAC/SARAR & SDEM \\
\hline \multirow{2}{*}{$D$} & 0.019 & $0.044^{* * * *}$ & $0.051^{* * * *}$ \\
\hline & $(1.228)$ & $(2.836)$ & $(3.105)$ \\
\hline \multirow{2}{*}{ Ininno } & $0.029^{* * *}$ & $0.050^{* * * *}$ & $0.055^{* * *}$ \\
\hline & $(4.503)$ & (7.087) & $(7.490)$ \\
\hline \multirow{2}{*}{ gov } & $0.088^{* * *}$ & $0.060^{*}$ & $0.066^{*}$ \\
\hline & $(2.622)$ & $(1.738)$ & (1.813) \\
\hline \multirow{2}{*}{$\operatorname{lnsO}_{2}$} & $-0.040^{* * * *}$ & $-0.037^{* * * *}$ & $-0.040^{* * * *}$ \\
\hline & $(-13.217)$ & $(-12.281)$ & $(-12.735)$ \\
\hline \multirow{2}{*}{ instru } & -0.002 & -0.004 & -0.003 \\
\hline & $(-0.341)$ & $(-0.882)$ & $(-0.619)$ \\
\hline \multirow{2}{*}{$\ln p g d p$} & 0.0198 & 0.024 & 0.024 \\
\hline & $(1.298)$ & $(1.610)$ & $(1.501)$ \\
\hline \multirow{2}{*}{ finance } & $-0.022^{* * * *}$ & $-0.020^{* * * *}$ & $-0.021^{* * * *}$ \\
\hline & $(-5.556)$ & $(-5.033)$ & $(-5.042)$ \\
\hline \multirow{2}{*}{$W^{*} D$} & & & $-0.057^{* *}$ \\
\hline & & & $(-2.097)$ \\
\hline \multirow{2}{*}{$W^{*} \operatorname{lninno}$} & & & $-0.054^{* * *}$ \\
\hline & & & $(-5.580)$ \\
\hline \multirow{2}{*}{$W^{*} g o v$} & & & 0.051 \\
\hline & & & $(0.914)$ \\
\hline \multirow[t]{2}{*}{$W^{*} \ln s \mathrm{O}_{2}$} & & & 0.002 \\
\hline & & & $(0.443)$ \\
\hline
\end{tabular}




\begin{tabular}{|c|c|c|c|}
\hline$W^{*}$ instru & & & $\begin{array}{c}0.012 \\
(0.992)\end{array}$ \\
\hline$W^{*} \ln p g d p$ & & & $\begin{array}{c}-0.017 \\
(-0.598)\end{array}$ \\
\hline$W *$ finance & & & $\begin{array}{c}0.005 \\
(0.695)\end{array}$ \\
\hline$W^{*}$ Gino $(\rho)$ & & $\begin{array}{l}-0.493^{* * * *} \\
(-12.772)\end{array}$ & \\
\hline$W^{*} \mu(\lambda)$ & & $\begin{array}{l}0.531^{* * * *} \\
(18.705)\end{array}$ & $\begin{array}{l}0.122^{* * * *} \\
(5.889)\end{array}$ \\
\hline Constant & $\begin{array}{l}0.524^{* * *} \\
(3.374)\end{array}$ & $\begin{array}{l}0.560^{* * * *} \\
(3.894)\end{array}$ & $\begin{array}{c}0.778 \\
(0.0043)\end{array}$ \\
\hline Spatial fixed effects & Yes & Yes & Yes \\
\hline Time fixed effects & Yes & Yes & Yes \\
\hline Adjusted R-squared & 0.599 & 0.538 & 0.603 \\
\hline Log-likelihood & 1175.8 & 1230.747 & 1221.718 \\
\hline AIC & -2337.600 & -2443.494 & -2415.436 \\
\hline LR-test & & $109.913^{* * *}$ & $91.855^{* * *}$ \\
\hline Robust LM-error & $27.255^{* * *}$ & & \\
\hline Robust LM-lag & $15.321^{* * *}$ & & \\
\hline Residuals Moran's I & $0.072^{* * *}$ & & \\
\hline Observations & 4560 & 4560 & 4560 \\
\hline
\end{tabular}

Notes: Numbers in parentheses are $t$-statistics. Significance at the $10 \%\left(^{*}\right), 5 \%\left({ }^{* * *}\right)$ or $1 \%$ level $\left({ }^{* * *}\right)$ is indicated.

In the SAC/SARAR model and the SDEM model, the dependent variable autocorrelation coefficient $\rho$ and the error term autocorrelation coefficient $\lambda$ are both significant at the $1 \%$ level, indicating significant spatial correlation characteristics of the dependent variable and the unobserved variable. Moreover, the explanatory variables in the SDEM model mostly have insignificant spatial spillover effects. Based on the comparison of the three models, this paper believes that the estimation result of the SAC/SARAR model is the most effective. Hence, this paper will further discuss the estimation result of SAC/SARAR model below.

Seen from the SAC/SARAR model in Table 2, the coefficient of the treatment effect $D$ of the variable concerned in this paper is significantly positive at the $1 \%$ level, indicating that the pilot policy of combining technology and finance has significantly promoted the development of regional green innovation. The pilot areas have adopted a series of policy measures to achieve the organic combination of technological innovation and financial capital, provide targeted financial services for technological enterprises at various stages of development from the initial stage to the mature stage, thus effectively promoting the green innovation of technological enterprises.

Seen from the perspective of related control variables, innovation results are significantly positive at the $1 \%$ level. The development of modern society not only imposes a higher requirement for production efficiency, but also raises more and more concern about environmental protection and health. Green itself represents innovation, and innovation also makes this society greener. The innovation results and green innovation efficiency are significantly positive, which is in line with the expectations of this paper. In the research on the factors influencing innovation efficiency, many documents introduce government funding for science and technology into the model as an important factor in the government efforts to improve the level of innovation efficiency. We believe that the government's leading role in green innovation is not only reflected in the direct investment in science and technology. The level of public education in a region, the green upgrade of public infrastructure, and the government's work efficiency and service capabilities can also create a positive and indirect effect in green innovation efficiency of the region. We can also see from the estimated results in Table 2 that the estimated 
coefficient of government expenditure is significantly positive at the level of $10 \%$, which verifies the previous hypothesis that we should not only pay attention to the direct scientific research investment in government expenditure, but also concern government spending in other areas. In this way, it is possible to fully promote the improvement of local green innovation efficiency.

The environmental pollution coefficient represented by the sulphur dioxide logarithmic value is significantly negative at the level of $1 \%$, indicating that the government's attitude and tolerance towards environmental pollution play a significant role in improving green innovation efficiency of the region. The variables of industrial structure and per capita GDP are insignificant, indicating that the upgrading of industrial structure and the rise of per capita GDP have not significantly promoted the improvement of green innovation level in the region. The coefficient of traditional financial variables is significantly negative at the $1 \%$ level. Traditional finance not just fails to promote green innovation efficiency in the region, but reduces the level of green innovation efficiency in the region. We believe that traditional financial models no longer meet the financial needs of modern social development, especially the financing needs of innovative technology companies. The estimated coefficient of traditional finance is significantly negative, which explains the necessity of implementing pilot policy of combining technology and finance. The spatial autoregressive coefficient of green innovation efficiency is significantly negative at the $1 \%$ level, indicating that the green innovation level of neighboring regions creates a negative effect on the development of green innovation in the region. Some scholars believe that as long as the central government releases strong achievement signals when it comes to emerging industries, due to the existence of local government industry preferences, the convergence of industrial structure will be formed under homogeneous competition on the basis of advantage deviation and exhibit solidification characteristics. We believe that this may be related to the homogeneous competition among various regions in China. The homogeneous competition among the green industries of various governments has affected the improvement of green innovation efficiency in various regions. The estimation results also further confirm the possible homogenous competition in technological green industries among local governments.

\subsection{Robustness test}

In this paper, the model is further subject to placebo test by changing the pilot cities and pilot time. First, a total of 49 cities were randomly selected as the treatment group during the two pilot periods and the remaining cities were used as the control group. Secondly, the two batches of pilots were artificially advanced by two years, namely 2009 and 2014. Substitute the transformed treatment effect $D$ ' into the SAC/SARAR model to test the pilot policy effect. If the coefficient is insignificant, it indicates that the increase in the efficiency of urban green innovation is caused by the technology and finance pilot police, rather than other factors. Otherwise, the conclusion is not robust.

The results show that by changing the pilot cities and pilot time of the treatment group in Table 3, the estimated coefficients of treatment effects are insignificant. It suggests that the improvement in the efficiency level of urban green innovation is indeed related to the technology and finance pilot policies. So far, according to the above-mentioned robustness test, the estimation results and conclusions are very robust.

Table 3 Results of placebo test

\begin{tabular}{ccc}
\hline & Pilot cities were randomly selected & The pilot period was 2 years in advance \\
\hline \multirow{2}{*}{$D^{\prime}$} & -0.008 & 0.014 \\
& $(-0.600)$ & $(0.879)$ \\
Ininno & $0.049^{* * * *}$ & $0.049^{* * * *}$ \\
& $(6.914)$ & $(6.987)$ \\
gov & 0.056 & 0.056 \\
& $(1.619)$ & $(1.642)^{* * *}$ \\
lnso & $-0.038^{* * *}$ & $-0.038^{* * *}$ \\
& $(-12.550)$ & $(-12.449)$ \\
instru & -0.004 & -0.004 \\
& $(-0.853)$ & $(-0.876)$ \\
\hline
\end{tabular}

ISSN: 0010-8189

C CONVERTER 2021

www.converter-magazine.info 


\begin{tabular}{ccc}
\hline lnpgdp & 0.022 & 0.023 \\
& $(1.459)$ & $(1.516)$ \\
finance & $-0.020^{* * * *}$ & $-0.020^{* * * *}$ \\
& $(-4.969)$ & $(-4.983)$ \\
$W^{*}$ Gino $(\rho)$ & $-0.485^{* * *}$ & $-0.487^{* * *}$ \\
$W^{*} \mu(\lambda)$ & $(-12.362)$ & $(-12.441)$ \\
& $0.524^{* * * *}$ & $0.525^{* * *}$ \\
Constant & $(18.013)$ & $(18.158)$ \\
Spatial fixed effects & $0.598^{* * *}$ & $0.583^{* * * *}$ \\
Time fixed effects & $(4.147)$ & $(4.040)$ \\
Adjusted R-squared & Yes & Yes \\
Log-likelihood & Yes & Yes \\
AIC & 0.540 & 0.539 \\
Observations & 1226.946 & 1227.151 \\
\hline
\end{tabular}

Notes: Numbers in parentheses are $t$-statistics. Significance at the $10 \%\left({ }^{*}\right), 5 \%\left({ }^{* *}\right)$ or $1 \%$ level $\left({ }^{* * * *}\right)$ is indicated.

\section{Conclusion and Discussion}

Through empirical research, it is found that the pilot policy of combining technology and finance has generally promoted the development of green innovation in various regions. At the same time, we have also found that local governments greatly affect the innovation effect of technology and finance pilot policy, exerting both positive and negative effects. First of all, the direct or indirect public expenditure of government departments and its strong attitude towards environmental protection will greatly support the local green innovation. Secondly, the strong achievement signal of green development stimulates local governments to prefer the development of green industries on the basis of advantage deviation, so that convergence of industrial structure leads to vicious homogeneous competition, which is not conducive to the improvement of green innovation efficiency. Based on the above analysis, we conclude the following policy enlightenments and thereby proposes development suggestions:

First, continue to implement the pilot policy of combining technology and finance. The state should further understand the implementation status of local technology and finance policies and increase support for local science and technology finance. By establishing a pioneer model of urban green innovation, it will drive green innovation activities in more cities and form shared experiences for green development cities. Second, increase government investment and strengthen environmental protection measures. These inputs not only refer to science and technology fiscal expenditures, but also include input in regional education resources, infrastructure, and government public service efficiency. The control of urban environmental pollution creates a strong incentive effect on local green innovation activities. It is necessary to strictly implement pollution discharge standards, increase the punishment of environmental pollution, and increase environmental protection publicity, so that environmental protection awareness is deeply rooted in the hearts of the people. Third, develop in an orderly manner in accordance with local conditions. Both choice of green industry and implementation of technology and finance policies should be tailored to local conditions. Financial policies should be formulated according to local actual conditions to meet specific market conditions, and appropriate green projects should be selected based on the advantages of local factor endowments. We should not blindly learn from them, not to mention copy them completely. Since green innovation features clustering, the state can concentrate its technology and finance resources in major rapidly developing cities to form a virtuous circle of technology-driven capital and capital-driven innovation, thereby driving the comprehensive development of green innovation activities in the entire region.

ISSN: 0010-8189

(C) CONVERTER 2021

www.converter-magazine.info 


\section{Acknowledgements}

This research was supported by Major Project of Philosophy and Social Science Research in Universities of Hubei Province (No. 20ZD102) and National Natural Science Foundation of China (No. 71473074).

\section{References}

[1] Y.X. Zhang, Q. Zhang, "Dynamic comprehensive evaluation of regional sci-tech financial ecosystem," Studies in Science of Science, vol. 36, no. 11, pp. 1963-1974, 2018.

[2] K. Tone, "Dealing with Undesirable Outputs in DEA: A Slacks-Based Measure (SBM) Approach," In Proceedings of the North American Productivity Workshop III, 2004.

[3] Q. Wang, S. She, Q.Q. Zeng, "The mechanism and effect identification of the impact of National High-tech Zones on urban green innovation: based on a DID test,"China Population Resources and Environment, vol. 30, no. 2, pp. 129-137, 2020.

[4] L.Y. Ma, X.M. Li, "Does Science and Technology Finance PoliciesPromote Regional Innovation? Quasi-natural Experiment Based on the Pilot Policy of Combining Science and Technology with Finance," China Soft Science, vol. 12, pp. 30-42, 2019.

[5] S.M. Zheng, Y.J. Wu, K. Zou, "Research on Policy Effect the Integration of Technology and Finance:Based on DID Model,"China Soft Science, vol.1, pp. 49-58, 2020.

[6] Y. Sunak, R.Madlener, "The impact of wind farm visibility on property values: A spatial difference-in-differences analysis," Energy Economics, vol.55, pp. 79-91, 2016.

[7] L. Anselin, D.Arribas-Bel, "Spatial fixed effects and spatial dependence in a single cross-section," Papers in Regional Science, vol. 92, no. 1, pp. 49-58, 2013.

[8] D.A. Griffith, L.Anselin, “Spatial econometrics: Methods and models Economic Geography,” Economic Geography,vol. 65, no. 2, pp. 160-162,1989.

[9] J. LeSage, R.K.Pace, "Introduction to spatial econometrics," Chapman and Hall/CRC, 2009.

[10] O.W. Lerbs, C.A.Oberst, "Explaining the spatial variation in homeownership rates: Results for german regions,” Regional Studies, vol. 48, no. 5, pp. 844-865,2014. 